\title{
PATIENTS' RISK STRATIFICATION IN THE MANAGEMENT OF OSTEOPOROSIS: THE LATEST INTERNATIONAL GUIDELINES
}

Dr Chionh Siok Bee

\begin{abstract}
Assessment of risk of a fragility fracture is a vital step a physician needs to undertake in every patient suspected of osteoporosis, as this will influence the decisions on whether to treat with a pharmacological agent, with which drug, and for how long. After risk stratification, patients deemed Very High-Risk should be considered for an anabolic agent, or if this is not feasible, a parenteral anti-resorptive. HighRisk or Moderate-Risk patients may be considered for oral bisphosphonates.
\end{abstract}

Key Words: Fracture, risk assessment, risk stratification, osteoporosis

\section{SFP202I; 47(3) : 8- 16}

In the 2019 European guidance for the diagnosis and management of osteoporosis in postmenopausal women ${ }^{1}$, it is strongly recommended that patients be stratified for risk of fragility fractures. High-Risk individuals should be treated with a pharmacological agent to reduce fracture risk. This includes patients who have already sustained fragility fractures. It is recommended for older individuals who have not had fragility fractures to assess the clinical risk factors and treat those identified as having a high risk for fracture. For people with Intermediate Risk, BMD may be performed to assist in decision-making (Figure 1).

FRAX is an excellent tool to calculate fracture risk in people age 40 years and above. It balances the 10-year risk of a fracture against the risk of mortality, unlike other tools such as the Garvan risk calculator, which gives only pure fracture risk, regardless of the likelihood of imminent mortality in older individuals. A country-specific, age-dependent Intervention Threshold (IT) using FRAX can be derived by entering the mean height and weight of an individual at each age group of that gender for the population and entering all risk factors in FRAX as NO except for the question of History of fracture, which is answered as Yes. This would give the 10-year risk of Major Osteoporotic Fracture, or risk of Hip Fracture, at which a typical individual of that age and gender would sustain a fragility fracture. A graph

\section{CHIONH SIOK BEE \\ Senior Consultant \\ Division of Endocrinology, University Medicine Cluster \\ National University Hospital}

Figure I. Management Algorithm for the Assessment of Individuals at Risk of Fracture

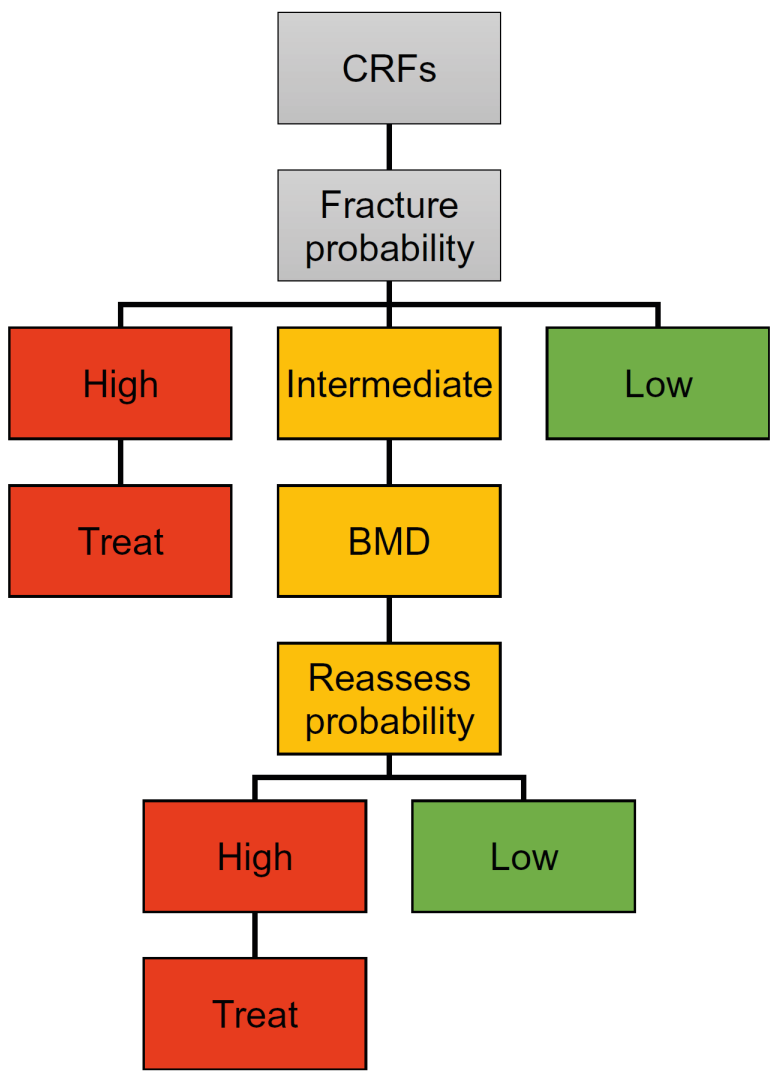

of Age-dependent Intervention Thresholds, for example in U.K., is shown in Figure 2. An Upper Assessment Threshold (UAT) can be set at 1.2 times of the Intervention Threshold, and a Lower Assessment Threshold (LAT) is set using all questions in FRAX answered as No. People below the LAT are deemed Low-Risk and merely need advice to optimise their lifestyle concerning diet and exercise. In addition, women with significant menopausal symptoms may be offered Menopausal Hormone Therapy if suitable.

In countries with limited access to DXA, people above the UAT may be deemed High-Risk and treated pharmacologically, even without a baseline BMD. People who fall between the LAT and UAT should have DXA BMD to refine risk assessment further: those with T-scores -2.5 and below may receive treatment, while those with osteopenia can have more refined FRAX scores to decide regarding treatment. The UK uses this model but has further refined it into a Hybrid Intervention Threshold (Figure 3). There is an age-dependent curve up to age 70 years, after which the fracture threshold remains fixed horizontally. Clicking on the "View NOGG Guidance" tab below the calculated 10-year risk results within the UK FRAX site brings one to the exact point in one of the three categories where the individual belongs to. 
Figure 2. 10-year Risk of Major Osteoporotic Fracture plotted against Age e.g. UK

Ten year probability (\%)

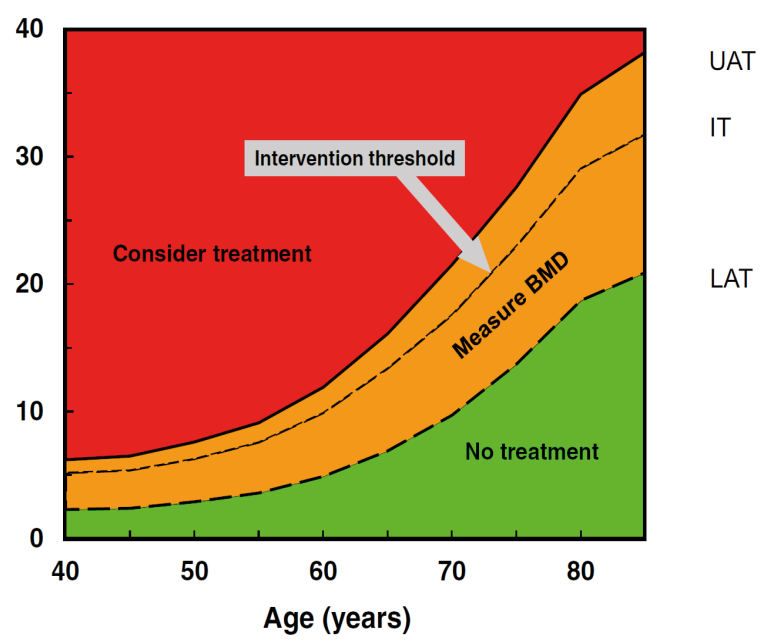

Figure 3. UK NOGG Guidance using a Hybrid Intervention Threshold

Welcome to the NOGG 2017 Guideline Update. These new thresholds ensure equality of access to treatment for older patients with and without fracture (for full details, see the Guideline document)

\section{Assessment threshold - Major fracture}

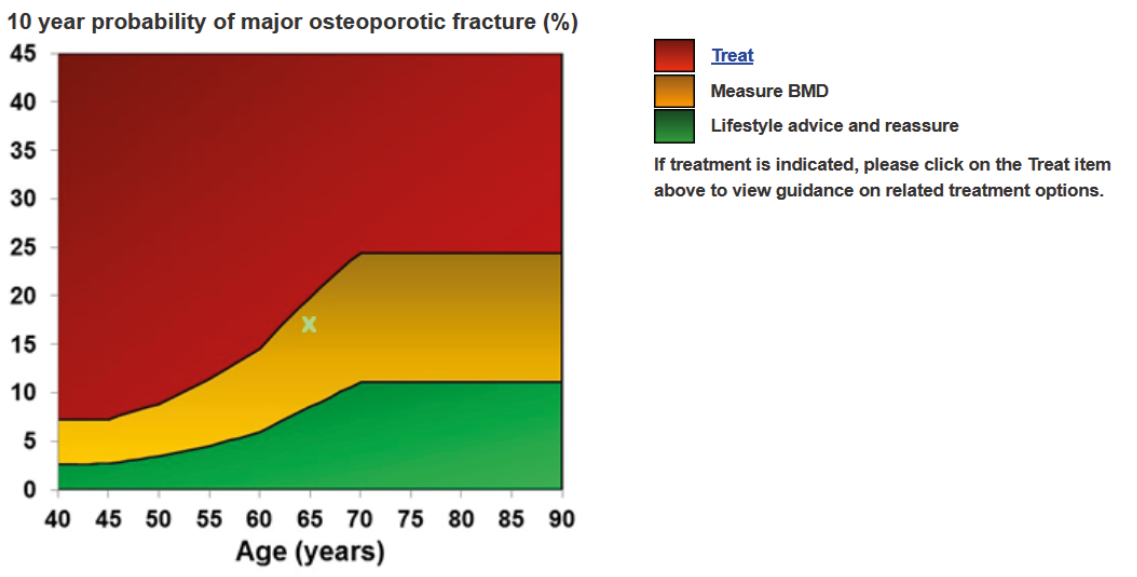


In countries with good access to DXA, for example Germany, anyone with no prior fractures who are above the LAT may be considered for BMD assessment to refine fracture risk further and treated if at risk (Figure 4).

Figure 4. BMD Assessment

Ten year probability (\%)

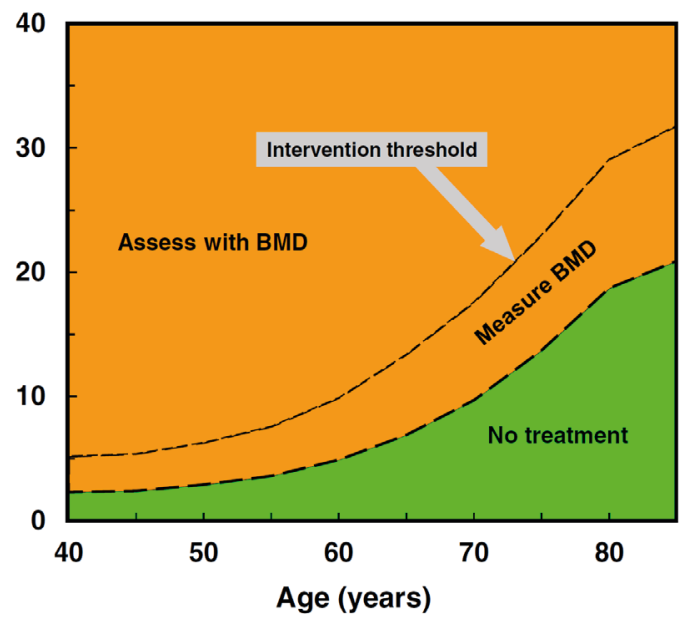

If Singapore were to use an age-dependent intervention threshold, it would be as featured in Figure $5 .{ }^{2}$ You may note the "low" intervention threshold for the 10-year probability of Major Osteoporotic Fracture at age 50-60 years. While the 10year risk is "low", the lifetime risk of a fragility fracture is high, and DXA measurement and treatment should be considered in people above the intervention threshold. This concept is similar to the concept of early statin treatment for Familial Hyperlipidaemia.

\section{Figure 5. Age-dependent FRAX-based Intervention Thresholds for Singapore}

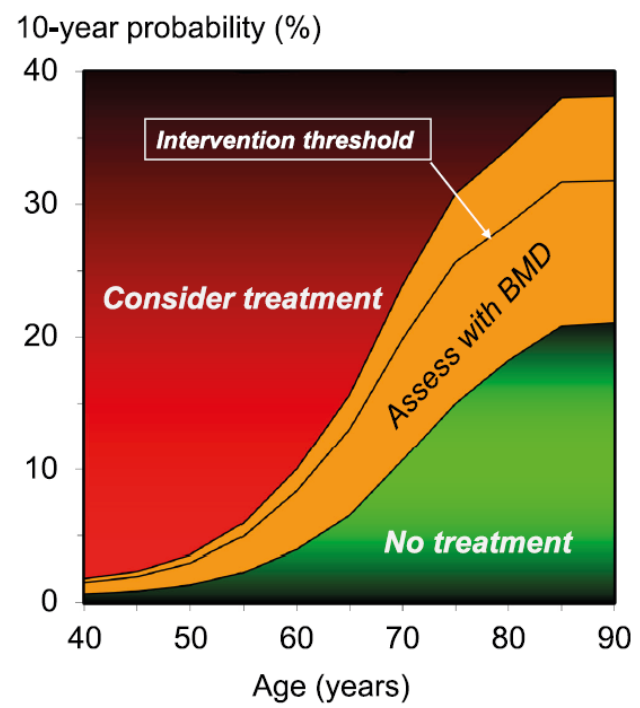

The Endocrine Society (USA) guidelines from $2019^{3}$ (Figure 6) further recommends stratifying At-Risk patients into Moderate-Risk and High-Very High Risk. In contrast with the age-dependent FRAX intervention thresholds recommended in Europe, the USA uses Fixed Intervention Thresholds based on pharmacoeconomic considerations from years ago, when generic oral bisphosphonates were not available. The intervention thresholds may likely be lower if similar pharmacoeconomic calculations were done now. Low-risk patients are those who have no prior hip or spine fractures, T-score $>-1.0$ and with FRAX scores $<20$ percent for Major Osteoporotic Fractures or $<3$ percent for hip fractures. They may be given lifestyle advice. Moderate-Risk patients may be considered for oral bisphosphonates. High-Risk patients (prior hip or spine fractures, T-scores $\leq-2.5$ or "Osteopaenia"/low bone mass with FRAX scores $\geq 20$ percent for Major Osteoporotic Fractures or $\geq 3$ percent for Hip fractures) and Very High-Risk patients (such as those with multiple spinal fractures with T-score $\leq-2.5$ ) may be considered for Teriparatide or Abaloparatide, Denosumab or Bisphosphonate. 
After treatment, if a patient is then assessed as Low-Risk, those on bisphosphonates can be considered for a drug holiday, while those on other agents, such as Teriparatide or Denosumab, need to be transitioned to a bisphosphonate first. Those assessed as continuing to have High-Risk should either continue treatment with the same agent or switch to another agent.

Figure 6. Algorithm for the Management of Postmenopausal Osteoporosis

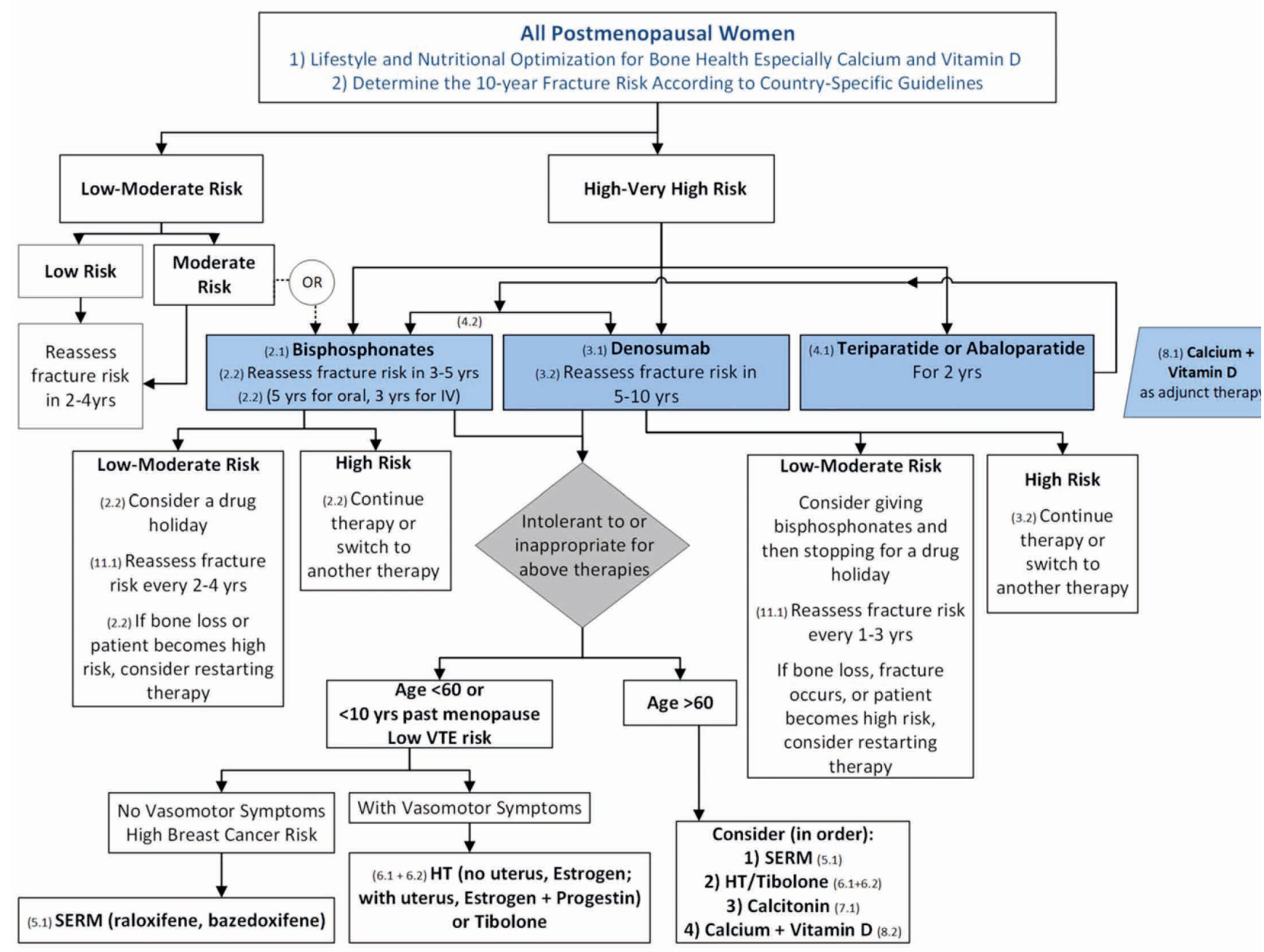


The American Association of Clinical Endocrinologists (AACE) guidelines published in $2020^{4}$ also identifies people At Risk as High-Risk or Very High-Risk (Figure 7). Those at Very High-Risk include people with previous fractures, or if there is a very low T-score, advanced age, frailty, falls, glucocorticoid usage. In this Very High-Risk group, consider using an anabolic agent, such as Teriparatide, Abaloparatide or Romosozumab, or a parenteral anti-resorptive such as Denosumab or Zoledronate.

Figure 7. The AACE 2020 Postmenopausal Osteoporosi

\section{AACE/ACE 2020 POSTMENOPAUSAL OSTEOPOROSIS TREATMENT ALGORITHM}

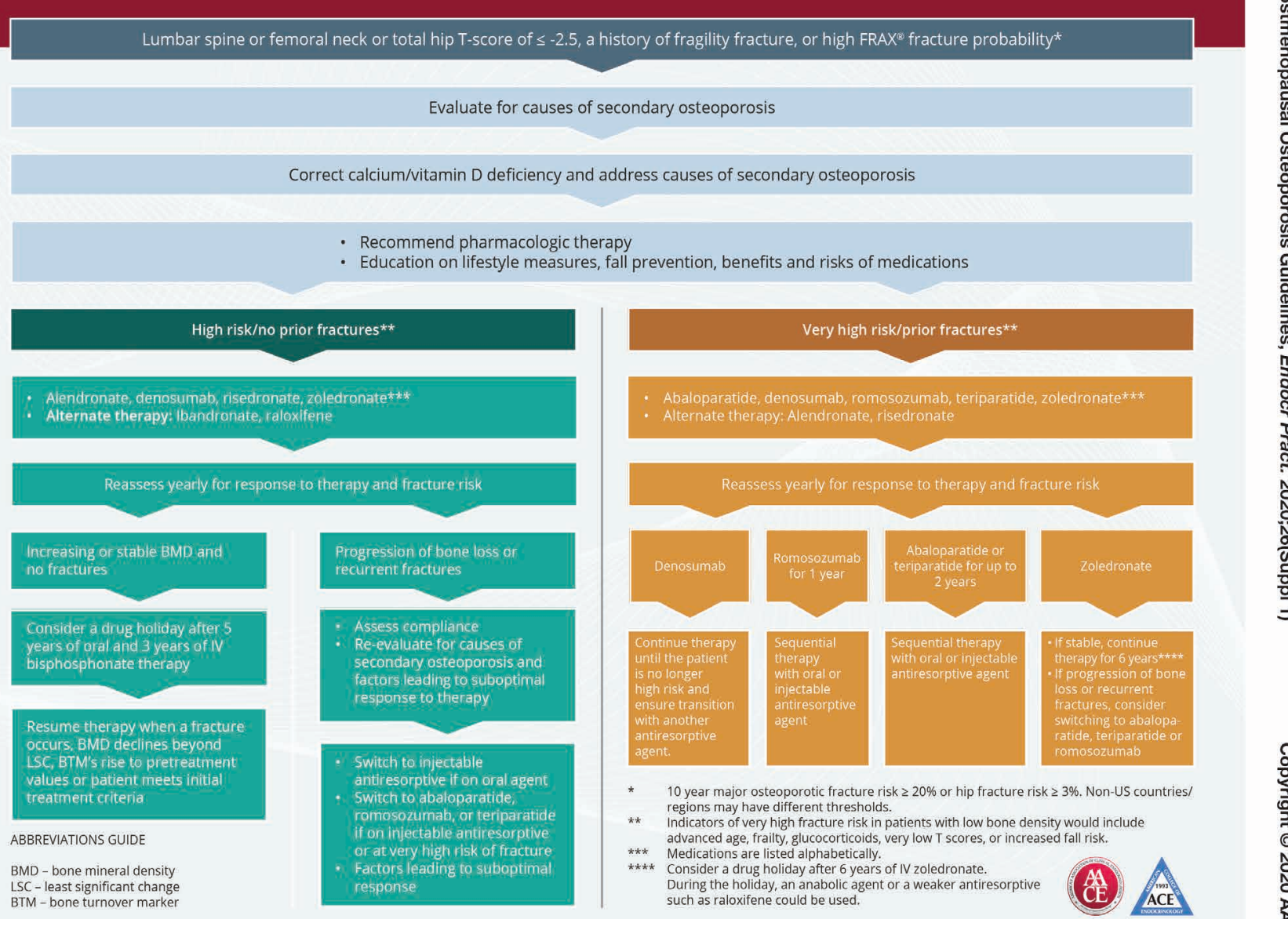




\section{REFINEMENTS IN FRAX SCORES FOR IMPROVED FRACTURE RISK PREDICTION}

In calculating FRAX scores, refinement of the fracture risk can be made in certain common clinical situations outside of the common clinical risk factors already in FRAX. These adjustments are for: -
A. Imminent fracture risk
B. Steroid dose
C. Presence of Type 2 Diabetes Mellitus
D. Frequent Falls
E. Spine-hip BMD discrepancy

A. Imminent Fracture Risk

Figure 8. Cumulative Risk of Subsequent Fracture within 5 Years

\section{High Imminent Risk of Another Fracture And High Risk of Mortality Within 5 years After A Fracture}

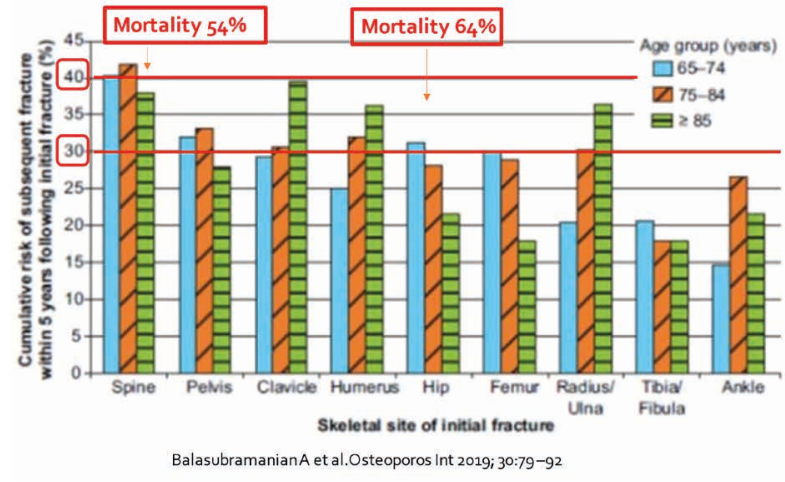

A recent fracture of the hip or spine, especially within the previous 2-5 years, dramatically increases the risk of another fracture (Figure 8). This increased fracture risk which is more than the FRAX prediction is higher in younger women, with women age 50 years having a 2.47 -fold increase in the risk of another fracture within two years of a prior clinical fracture, compared to the cohort with any fracture during adult life (as calculated by FRAX), while for women age 80 years, the increase is only 1.24-fold (Table 1 ). ${ }^{5}$
Table I. I0-year Probability of MOF

\begin{tabular}{|c|c|c|c|}
\hline \multirow[b]{2}{*}{ Age } & \multicolumn{2}{|c|}{ 10-year Probability of MOF } & \multirow[t]{2}{*}{ Ratio } \\
\hline & $\begin{array}{l}\text { Cohort with } \\
\text { Clinical } \\
\text { Fracture 0-2 } \\
\text { years Ago }\end{array}$ & $\begin{array}{l}\text { Cohort with } \\
\text { Any Fracture } \\
\text { in Adult Life }\end{array}$ & \\
\hline 50 & 29.0 & 11.7 & 2.47 \\
\hline 60 & 36.1 & 19.4 & 1.86 \\
\hline 70 & 41.9 & 27.6 & 1.52 \\
\hline 80 & 42.5 & 34.2 & 1.24 \\
\hline 90 & 34.7 & 33.3 & 1.04 \\
\hline
\end{tabular}

\section{B. Steroid Dose}

When Prednisolone doses are lower than $2.5 \mathrm{mg}$ daily or higher than $7.5 \mathrm{mg}$ daily, the effect on FRAX can be modified downwards or upwards, respectively (Table 2). ${ }^{6}$

Table 2. Percentage adjustment of I0-year probability of a hip fracture or a major osteoporotic fracture by age according to the dose of glucocorticoids

\begin{tabular}{|c|c|c|c|c|c|c|c|c|}
\hline \multirow[t]{2}{*}{ Dose } & \multirow[t]{2}{*}{ Prednisolone equivalent (mg/day) } & \multicolumn{6}{|c|}{ Age (years) } & \multirow[b]{2}{*}{ All ages } \\
\hline & & 40 & 50 & 60 & 70 & 80 & 90 & \\
\hline \multicolumn{9}{|l|}{ Hip fracture } \\
\hline Low & $<2.5$ & -40 & -40 & -40 & -40 & -30 & -30 & -35 \\
\hline Medium $^{\mathrm{a}}$ & $2.5-7.5$ & & & & & & & \\
\hline High & $\geq 7.5$ & +25 & +25 & +25 & +20 & +10 & +10 & +20 \\
\hline \multicolumn{9}{|c|}{ Major osteoporotic fracture } \\
\hline Low & $<2.5$ & -20 & -20 & -15 & -20 & -20 & -20 & -20 \\
\hline Medium $^{\mathrm{a}}$ & $2.5-7.5$ & & & & & & & \\
\hline High & $\geq 7.5$ & +20 & +20 & +15 & +15 & +10 & +10 & +15 \\
\hline
\end{tabular}

a. No adjustment required

\section{Presence of Type 2 Diabetes Mellitus}

Patients with Type 2 DM have relatively good BMD but poor bone quality, such that the risk of hip fracture is 1.32.0 fold that of patients without Type 2 DM. When using FRAX for fracture prediction, apply a "penalty" for BMD in T2DM patients by choosing one of the following ${ }^{7}$ :

1. Lower T-score by 0.5 (-0.5) (Figure 10$)$

2. Input Rheumatoid Arthritis (RA) as "Yes" (Figure 9); this also applies to people with SLE

3. Use Trabecular Bone Score (TBS) (Figure 11) 


\section{FRAX using Hip FN BMD 0.6 and RA "No" -> NHANES T-score -2.2}

\section{Calculation Tool}

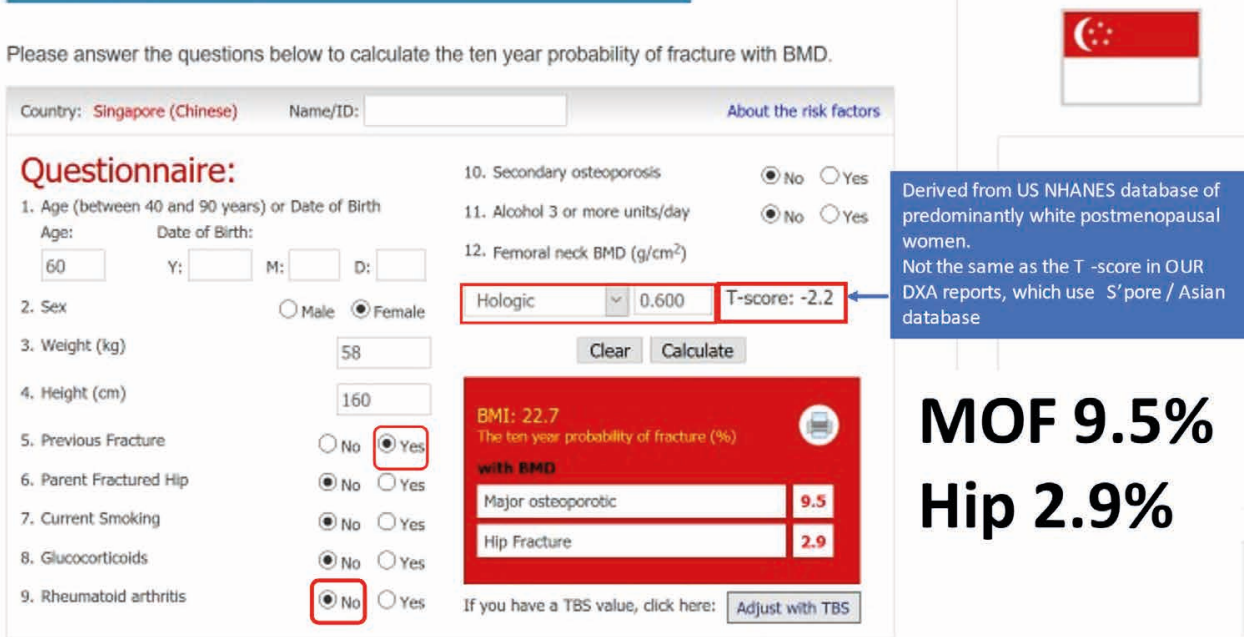

Figure 9. Input Rheumatoid Arthritis (RA) as "Yes"

\section{FRAX using Hip FN BMD 0.6 and RA "Yes", T-score -2.2}

\section{Calculation Tool}

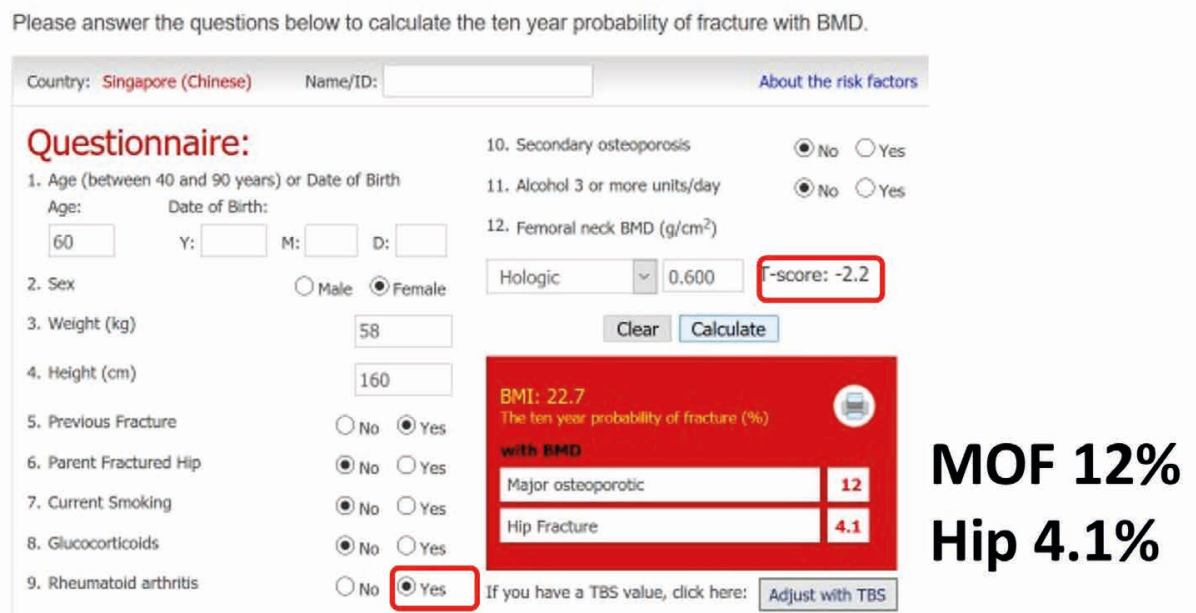


Figure 10. Lower T-score by 0.5

\section{Lowering T-score by 0.5 :}

\section{FRAX using T-score -2.7 in Hip FN}

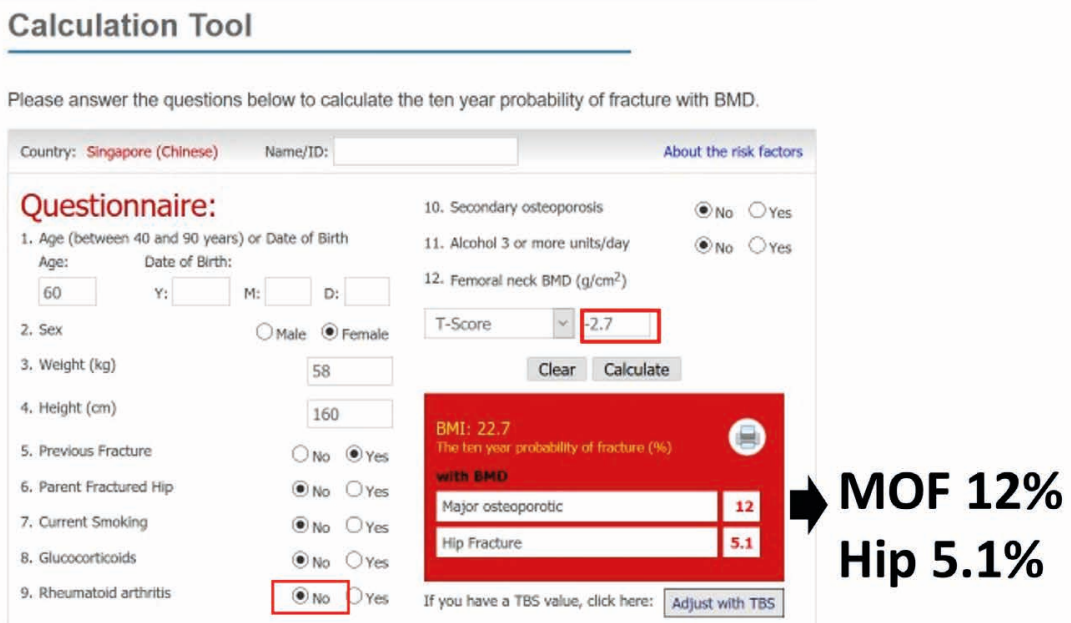

Figure I I. Trabecular Bone Score

\section{"Penalty" for T2 DM patients when using FRAX for} fracture prediction:

\section{Use Trabecular Bone Score (TBS)}

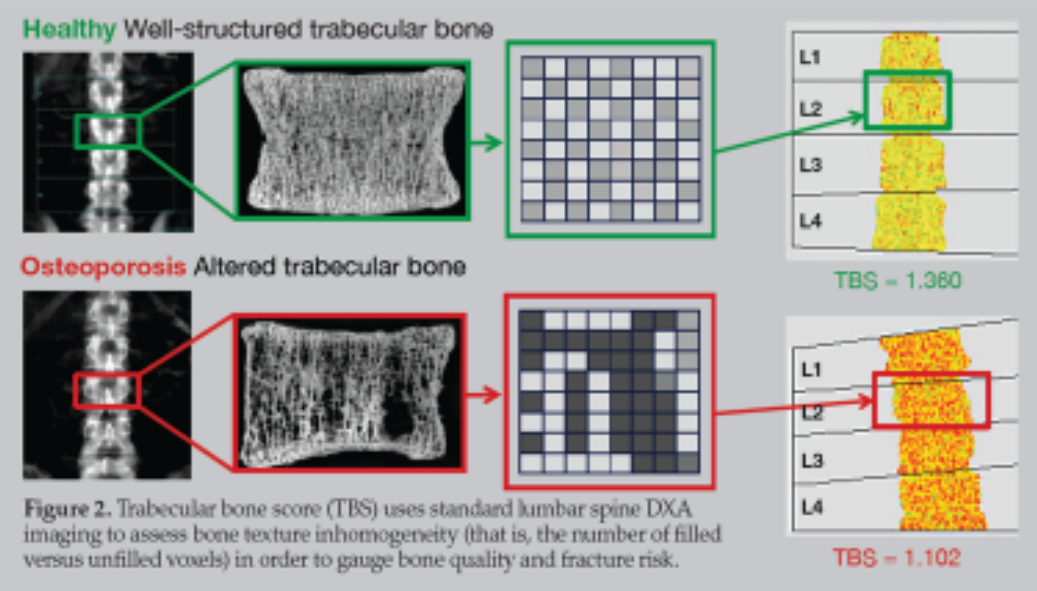

TBS is derived from DXA spine image measurements of gray-level texture inhomogeneity: an index of bone microarchitecture or bone quality. It has been incorporated in FRAX ${ }^{\mathrm{TM}}$ for fracture prediction in WHO and ISCD guidelines in 2015 


\section{Frequent Falls}

The hazards ratio for Major Osteoporotic Fracture and Hip Fracture for fallers are shown in Table 3 below $^{8}$ :

\begin{tabular}{|c|c|c|c|c|}
\hline $\begin{array}{c}\text { No. of } \\
\text { Falls }\end{array}$ & $\begin{array}{c}\text { HR Major } \\
\text { Osteoporotic } \\
\text { Fracture }\end{array}$ & $95 \%$ CI & $\begin{array}{c}\text { HR Hip } \\
\text { Fracture }\end{array}$ & $95 \%$ CI \\
\hline 1 & 1.49 & $1.26-1.78$ & & \\
\hline 2 & 1.74 & $1.33-2.77$ & & \\
\hline$\geq 3$ & 2.62 & $2.06-3.34$ & 3.41 & $2.19-5.31$ \\
\hline
\end{tabular}

E. Spine-Hip BMD discordance

Increase FRAX estimates by one tenth for every T-score of 1 that the Lumbar Spine T-score is lower than the Femoral Neck T-score in the DXA BMD results. ${ }^{9}$ For example, if the Lumbar Spine T-score is -3.0 and the Femoral Neck T-score is -2.0 , the FRAX scores should be increased by one tenth or ten percent.

\section{REFERENCES}

I. Kanis JA, Cooper C, Rizzoli R, Reginster JY; Scientific Advisory Board of the European Society for Clinical and Economic Aspects of Osteoporosis (ESCEO) and the Committees of Scientific Advisors and National Societies of the International Osteoporosis Foundation (IOF). European guidance for the diagnosis and management of osteoporosis in postmenopausal women. Osteoporos Int. 2019 Jan;30(I):3-44. doi: 10.1007/s00198-0184704-5. Epub 2018 Oct I5. Erratum in: Osteoporos Int. 2020 Jan;3I(I):209. Erratum in: Osteoporos Int. 2020 Apr;3I(4):80I. PMID: 303244I2; PMCID: PMC7026233.

2. Kanis JA, Chandran M, Chionh SB, Ganeson G, Harvey NC, Koh WP, Kwok T, Lau TC, Liu E, Lorentzon M, McCloskey EV, Tan KB, Vandenput L, Johansson $H$. Use of age-dependent FRAX-based intervention thresholds for Singapore. Arch Osteoporos. $2020 \mathrm{Jul}$ 22; I 5( I): I04. doi: I0. I007/s I | 657-020-00782-9. PMID: 32700 I I 8; PMCID: PMC7376084.
3. Eastell R, Rosen CJ, Black DM, Cheung AM, Murad MH, Shoback D. Pharmacological Management of Osteoporosis in Postmenopausal Women:An Endocrine Society* Clinical Practice Guideline.J Clin Endocrinol Metab. 2019 May I;104(5):I595-1622. doi: 10.1210/ jc.2019-0022I. PMID: 30907953.

4. Camacho PM, Petak SM, Binkley N, Diab DL, Eldeiry LS, Farooki A, Harris ST, Hurley DL, Kelly J, Lewiecki EM, PessahPollack R, McClung M, Wimalawansa SJ, Watts NB. AMERICAN ASSOCIATION OF CLINICAL ENDOCRINOLOGISTS/ AMERICAN COLLEGE OF ENDOCRINOLOGY CLINICAL PRACTICE GUIDELINES FOR THE DIAGNOSIS AND TREATMENT OF POSTMENOPAUSAL OSTEOPOROSIS-2020 UPDATE. Endocr Pract. 2020 May;26(Suppl I): I-46. doi: I0.4I58/ GL-2020-0524SUPPL. PMID: 32427503.

5. Johansson H, Siggeirsdóttir K, Harvey NC, Odén A, Gudnason V, McCloskey E, Sigurdsson G, Kanis JA. Imminent risk of fracture after fracture. Osteoporos Int. 2017 Mar;28(3):775-780. doi: 10.1007/s00198-016-3868-0. Epub 2016 Dec 27. PMID: 28028554; PMCID: PMC5338733.

6. Kanis JA, Johansson H, Oden A, McCloskey EV. Guidance for the adjustment of FRAX according to the dose of glucocorticoids. Osteoporos Int. 20II Mar;22(3):809-16. doi: 10.1007/s001980I0-I524-7. Epub 20I I Jan I3. PMID: 2 I 229233.

7. Ferrari SL, Abrahamsen B, Napoli N, Akesson K, Chandran M, Eastell R, El-Hajj Fuleihan G, Josse R, Kendler DL, Kraenzlin M, Suzuki A, Pierroz DD, Schwartz AV, Leslie WD; Bone and Diabetes Working Group of IOF. Diagnosis and management of bone fragility in diabetes: an emerging challenge. Osteoporos Int. 2018 Dec;29(I2):2585-2596. doi: I0.1007/s00198-0I8-4650-2. Epub 2018 Jul 3I. PMID: 30066 I 3 I; PMCID: PMC6267I 52.

8. Leslie WD, Morin SN, Lix LM, Martineau P, Bryanton M, McCloskey EV, Johansson H, Harvey NC, Kanis JA. Fracture prediction from self-reported falls in routine clinical practice: a registry-based cohort study. Osteoporos Int. 2019 Nov;30(I I):2195-2203. doi: 10.1007/s00198-019-05106-3. Epub 2019 Aug 2. PMID: 313727I I.

9. Leslie WD, Lix LM, Johansson H, Oden A, McCloskey E, Kanis JA. Spine-hip discordance and fracture risk assessment: a physician-friendly FRAX enhancement. Osteoporos Int. 201I Mar;22(3):839-47. doi: 10.1007/s00198-010-|46I-5. Epub 2010 Oct 20. PMID: 2095996I.

\section{LEARNING POINTS}

- Accurate fracture risk prediction using a tool such as FRAX is necessary, and adjustments should be made for imminent fracture risk, presence of T2DM, steroid dose, frequent falling and spine-hip BMD discordance.

- Each country should decide whether to use age-dependent, fixed or hybrid intervention thresholds for FRAX-based treatment decisions.

- After risk stratification, patients can be managed according to their risk category as below:

Suggested Therapeutic Options in the Management of Postmenopausal Women

\begin{tabular}{|l|l|l|}
\hline \multicolumn{1}{|c|}{ Low-Risk } & \multicolumn{1}{|c|}{ High-Risk } & \multicolumn{1}{c|}{ Very High-Risk } \\
\hline Lifestyle measures & Alendronate & $\begin{array}{l}\text { Anabolic agent (Teriparatide, } \\
\text { Abaloparatide, or Romosozumab) followed } \\
\text { by anti-resorptive }\end{array}$ \\
\hline $\begin{array}{l}\text { Menopausal hormone therapy if } \\
\text { menopausal symptoms }\end{array}$ & Risedronate & \\
\hline Raloxifene if low spine BMD & IV Zoledronate & IV Zoledronate \\
\cline { 2 - 3 } & SC Denosumab & SC Denosumab \\
\hline
\end{tabular}

